\title{
How cigarette additives are used to mask environmental tobacco smoke
}

\author{
Gregory N Connolly, Geoffrey D Wayne, Denise Lymperis, Melissa C Doherty
}

\begin{abstract}
Objective-To understand the tobacco industry's research on and use of cigarette additives that alter the perception of exposure to environmental tobacco smoke (ETS).
\end{abstract}

Data sources-Internal documents from four websites maintained by the major US tobacco manufacturers and company patents pertaining to the use of ETS altering additives obtained from the US Patent and Trademark Office online database.

Study selection-Electronic searches of the four industry websites and the US patent database were conducted using keywords to identify relevant data.

Data extraction-Industry documents and patents obtained using an exploratory snowball sampling method were reviewed and grouped into four general categories according to whether the additive(s) described affected ETS visibility, odour, irritation, or emissions. Accuracy of isolated findings was validated through cross comparison of the data sources.

Data synthesis-Results of this preliminary study provide evidence that tobacco manufacturers have conducted extensive research on the use of chemical additives to reduce, mask, or otherwise alter the visibility, odour, irritation, or emission of ETS.

Conclusions-Findings suggest that the tobacco industry uses additives to reduce the perception of ETS. To protect the public, appropriate regulation of tobacco additives should be mandated.

(Tobacco Control 2000;9:283-291)

Keywords: environmental tobacco smoke; tobacco

Massachusetts Tobacco Control Program, Massachusetts Department of Public Health, Boston, Massachusetts, USA

G N Connolly

G D Wayne

D Lymperis

M C Doherty

Correspondence to: Gregory N Connolly, DMD, $\mathrm{MPH}$, Director

Massachusetts Tobacco Control Program,

Massachusetts Departmen of Public Health, 250 Washington Street, Boston Massachusetts 12108, USA; greg.connolly@state.ma.us

Received 13 January 2000 and in revised from 5 May 2000 . Accepted 17 May 2000
Keywords: environmental to
industry; additives; masking

Involuntary exposure to environmental tobacco smoke (ETS) causes lung cancer in healthy adult non-smokers, with an estimated 3000 deaths occurring annually in the USA. ${ }^{1}$ ETS exposure is also an important risk factor for coronary heart disease ${ }^{2}$ and is linked to respiratory illness in children. ${ }^{1}$ The tobacco industry has aggressively challenged these findings, and has opposed laws intended to protect non-smokers from exposure to secondhand smoke. ${ }^{3}$ A review of the tobacco industry documents indicates that manufacturers employ additives and other cigarette design technologies to alter the visibility, odour, and irritating quality of ETS without necessarily reducing the overall level of smoke or its constituents, or testing for alterations in smoke toxicity. These documents suggest that this practice is part of an overall campaign to counter the decline in the social acceptability of smoking.

Research performed by the tobacco companies revealed that smokers and non-smokers were bothered by ETS, and that smokers would prefer cigarettes that made smoking more socially acceptable. A 1981 Philip Morris document summarising two idea sessions on "beneficial additives", which were attended by senior management, including chief executive officer Hamish Maxwell, notes: "An additive that would reduce the stale smoke and butt odor, but would be tasteless itself might be useful." ${ }^{4}$ These same sessions resulted in the concept of a smoking device that could be refilled with additives to deliver "flavours" without smoke. This device closely resembles Philip Morris' smokeless cigarette, Accord, introduced in $1998 .^{5}$

The tobacco industry conducted extensive research on ETS altering additives. Internal code names, such as "Project Stealth", were often assigned to product prototypes as they underwent testing. ${ }^{6}$ Some were later introduced to the market as familiar brand names, such as Virginia Super Slims, Chelsea, and Horizon. This research focused primarily on using additives to reduce or mask the natural warning signs (for example, bad odour) of ETS exposure, rather than reducing actual smoke emissions. The tobacco industry has never fully or accurately disclosed these actions to either the public or government health agencies. Furthermore, this review produced only limited evidence of the manufacturers performing analyses to determine the impact of additives on the levels of mainstream and sidestream smoke constituents or smoke toxicity.

\section{Methods}

This is an exploratory study, using what is essentially a snowball sampling method in which documents culled from an initial search of general keywords and related synonyms (for example, environmental tobacco smoke, ETS, secondhand smoke, sidestream smoke, SS) were reviewed and used to develop further search headings. Data were collected through an online search of the US Patent and Trademark Office database (available from 1976 to the present, at www.uspto.gov) and the internal tobacco industry documents made publicly available through the Minnesota litigation and the recent Master Settlement Agreement. Comparison of these two 
complementary sets of data provided a means for checking the accuracy of isolated findings.

Keyword searches under a variety of headings (that is, additives, odour, visibility) permitted the identification of 300 industry patents. These patents were reviewed for claims of affecting sidestream smoke and then sorted into four general categories according to whether the additive(s) described reduced smoke irritation, odour, visibility, or emissions. The additive names and their categorisation were entered into a database for review and analysis.

The second source of data, the tobacco industry internal documents, were obtained through online sites maintained by the four major US tobacco manufacturers (www. pmdocs.com, www.rjrtdocs.com, www. bwdocs.com, and www.lorillarddocs.com). Documents obtained from the initial keyword search, supplemented by documents from the search of industry patents, were used to identify the names of key additives, the impact of additives on perception of ETS exposure and smoke toxicity, names of individuals who conducted relevant research, and project names or codes directly addressing sidestream issues. Further research followed from documents unearthed through exploration of these identified names and codes. This resulted in the selection of approximately 250 documents, which were also categorised into four groups according to the purpose of the additive and analysed for content. These documents are identified by the Bates number assigned to all documents produced in litigation.

\section{Results}

INDUSTRY RESEARCH ON CONSUMERS AND ETS Tobacco manufacturers conducted extensive consumer research involving both smokers and non-smokers to determine if cigarettes that produced less smoke and odour would reduce concerns about exposure to ETS and make smoking in public more acceptable. A 1991 Philip Morris report on "social" cigarette brands introduced to the market to address these concerns revealed that:

- "Low smoke/low odor concepts g[e]nerally receive positive response from smokers.

- About $1 / 2$ of non-smokers feel that people smoking around them is a "real annoyance".

- About $1 / 3$ of smokers say the[y] are bothered by smoke and odor."7

The report notes that despite evidence of an "unmet consumer need", past "sociallyoriented" products, such as RJ Reynolds' Premier (a novel nicotine delivery device), Vantage Excel, and Chelsea (reintroduced in 1990 as Horizon), have not succeeded in the marketplace. It also calls for promoting future "socially acceptable" brands to three potential smoker population segments. The first is the "socially motivated" group ( $42 \%$ of smokers) who are interested in a product that will "help ease tensions between smokers and nonsmokers". The second is the "socially and personally motivated" group (22\% of smokers), who are concerned about how they are perceived by others and are trading off smoking satisfaction for personal comfort. The third is the "personally motivated" segment (10-15\% of smokers), who are "personally bothered" by smoke and odour in their clothes, hair, home, and car.

The results of Philip Morris' "low sidestream/low odor" research revealed a high overall consumer interest in a socially acceptable cigarette. $^{8}$ Females were more interested than males, as were smokers who felt uncomfortable smoking around others. Based on these findings and the results of tests on several prototypes, future directions for more socially acceptable products were set forth: "Assuming minimal taste sacrifice:

- Neutralize or reduce lingering smoke odor.

- Reduce/mask ambient smoke odor, visibility, and irritation.

- Light, pleasant (detectable) aroma."

The growing importance of the social acceptability issue is elaborated upon in the Philip Morris 1993-1997 strategic plan, which notes: “ . . an increasing number of restrictions is imposed on smokers in the work place and public facilities. Anti-smoking zealots are applying social pressure on smokers in a variety of ways." 9

Two approaches to addressing this issue are recommended: reduced sidestream odour and irritation. "Consumer research indicates that odor is a significant issue. There is substantial opinion that sidestream irritation may also be an issue. These topics must be addressed as they are among the remaining possibilities for improvement of the social acceptance of smoking." 9

The five year plan indicates that Philip Morris intended to explore three strategies for developing socially acceptable products. The goal of the "reduced sidestream visibility" project was "to obtain a full circumference cigarette with approximately $70 \%$ visible sidestream reduction". 9 The use of two cigarette paper additives was being explored: "Completion of evaluation of magnesite as a sidestream reduction cigarette paper additive is scheduled for second quarter 1993. Development of calcium carbonate papers for reduced sidestream is scheduled for completion third quarter 1993."9

Two additional projects focused on the reduction of sidestream irritation and odour: "The goal of this program is to reduce sidestream irritation with special emphasis on the smoker. Analytical studies combined with subjective results will be used to investigate the relationships between sidestream smoke composition and irritation." "Conditional approval has been obtained to use CR2978 as a sidestream odor modification additive for conventional cigarette papers." 9

However, the plan does not call for reducing ETS particulates, nor does it state the need to test the smoke for altered toxicity.

Philip Morris' research on socially acceptable cigarettes included studying the role of the trigeminal and olfactory nerves in the sensory perception of secondhand smoke in order to develop "improved" products that contained fewer and less potent trigeminally 
active substances. ${ }^{10}$ This research involved a collaborative effort with Dr Robert RH Anholt and Dr Sidney A Simon of Duke University Medical Center. ${ }^{10}{ }^{11}$ According to a draft of their research proposal, one objective was to develop electrophysiological techniques to measure sidestream smoke induced trigeminal nerve activity. ${ }^{10}$ The efficacy of ocular, nasal, and oral stimuli in eliciting trigeminal responses would be determined, as well as the relative potencies of defined cigarette smoke components in eliciting olfactory and trigeminal responses. The proposal states: "These studies are likely to facilitate the development of tobacco products that generate sidestream smoke which retains desirable fragrance, but elicits minimal trigeminal sensations." 10

Lorillard also conducted research on consumers and ETS with an eye toward product development in mind. A November 1979 company memorandum states that " . . smokers are increasingly sharing the non-smokers' perception of smoking as a negative, irritating habit", and that the smoker is "more self-conscious about smoking". ${ }^{12}$ The suggested solution: "It is felt that the best "first step' product would be one with a significant and obvious reduction in the sidestream which seems to be one of the non-smokers' main complaints. This would give the smoker a feeling of being less offensive and an obvious 'conversation piece'." 12

RJ Reynolds conducted consumer aroma testing with the goal of developing a product with a pleasant sidestream aroma targeted toward young women (YW) smokers. ${ }^{13} \mathrm{~A}$ total of 54 aromas delivered in sidestream smoke were screened. Qualitative research revealed that the key perceived "benefits" of this product attribute most relevant to YW smokers were:

- "heightened and improved smoking sensory experience/smoothness;

- reduced cosmetic concerns (that is, less negative stale odor on hair and clothes)."13

This project led to the development of "Project TF" ("Tomorrow's Female"), which was targeted toward 18-34 year old women smokers "who want a fresher, cleaner smoking experience."14 The benefits of this product were:

- "smooth, satisfying taste;

- light/pleasant aroma and aftertaste;

- less sidestream smoke."14

MECHANISM OF ACTION OF ADDITIVES THAT ALTER ETS

The industry documents and patents suggest that many ETS altering additives reduce or mask the visibility, odour, or irritation of sidestream smoke without reducing its overall amount. While some additives are claimed to reduce ETS emissions, the question is, what is actually reduced? Many of the patents for these additives claim a reduction in ETS as a whole. But ETS has two components: a particulate phase, which is the visible smoke emanating from the lit end of the cigarette, and a gas phase, which is invisible. Some additive patents explicitly state that they reduce only the particulate matter. With other additives, the effect is stated more vaguely. It appears that many of the additives claimed to reduce ETS generally are, in fact, designed to reduce visible ETS only, apparently by converting it into gaseous invisible sidestream smoke. Two industry patents for double layer cigarette wrappers containing sidestream reducing additives provide examples. The first is a 1985 RJ Reynolds patent for a wrapper that contains an alkali metal salt burn additive, such as potassium citrate: "Here, the total amount of material released into the atmosphere during static burning may not be affected, but the droplets which constitute the particulate phase are reduced and the resultant stream is rendered invisible. The resulting smoke is thought to be less irritating, and thus less objectionable to consumers. This approach has yielded several candidates for a practical reduced-sidestream cigarette." ${ }^{\prime 15}$

The second is a 1990 Brown \& Williamson patent describing the use of several sidestream reducing wrapper additives (for example, aluminum and other metal hydroxides, alumina, and Attapulgite clay) that can be used singly or in combination: "The sidestream reducing compound is effective to reduce visible sidestream smoke components without effecting a marked, if any, reduction in gas phase components of sidestream smoke."

The goal of reducing the "annoying" effects of sidestream smoke, rather than actual emissions, is also apparent in a 1989 RJ Reynolds document that summarizes two brainstorming sessions of the "Sidestream Irritation Team": "Most smokers find the eye/nose irritation more annoying than the sidestream itself. Therefore, if the irritation was eliminated there would be no need to eliminate or reduce sidestream." ${ }^{17}$

While some additive patents specifically state an aroma masking effect, others refer to "improving" or "enhancing" the aroma of the sidestream smoke, as shown by the example in the box on page 286 . Note that in this patent, the effect of the additive on sidestream aroma could be viewed as incidental to flavour improvements in the mainstream smoke.

RJ Reynolds highlighted its odour enhancing technology in a 1989 advertisement introducing Chelsea, "the first cigarette that smells good", which was marketed as a "women's" brand (fig 1). ${ }^{18}$ The pamphlet features a "scratch 'n sniff" strip that releases the cigarette's aroma for the reader to sample.

\section{ADDITIVES THAT REDUCE/MODIFY SIDESTREAM} ODOUR

A 1981 Philip Morris memo summarising two "idea sessions" on reducing sidestream states: "It was suggested that we determine the chemical composition of those compounds which are most objectionable in sidestream aroma. Once identified, they could either be masked through additives or reduced."19

A 1988 Philip Morris memo lists 11 additives (for example, acetylpyrazine, anethole, limonene) that were selected for testing 
Typical patent language for additives that affect the aroma of ETS

- This invention provides smoking compositions which contain a $\beta$-hydroxygamma-ketoester compound as a flavorant-release additive.

- In one of its embodiments, this invention provides tobacco compositions which contain a flavorant-release additive such as dodecyl 3-hydroxy-2,2,3-trimethyl-4oxopentanoate: [see original patent for chemical structure diagram].

- Under cigarette smoking conditions the above illustrated $\beta$-hydroxy-gammaketoester pyrolyzes into 2,3-butanedione and other products which enhance the flavor of the mainstream smoke and the aroma of the sidestream smoke [emphasis added].

^US Patent No. 4,701,282. “ $\beta$-hydroxygamma-ketoester flavorant-release additives." Philip Morris Incorporated (assignee-at-issue), October 20, 1987.

to determine if they would modify sidestream odour. $^{20}$ Of note is the fact that these compounds were selected because they likely had low odour thresholds and few or no components that would elicit a trigeminal nerve response. Another memo from that year describes a deodorising additive developed by Union Carbide called "Smellrite" as "a highly effective adsorbent for odors." ${ }^{\text {"1 }}$ Smellrite was subsequently evaluated by a smoking panel, but was found to have no effect on sidestream aroma, although another experiment indicated that it did produce a marginal decrease in the overall intensity of cigarette butt odour. ${ }^{22}$ Other Philip Morris odour altering compounds included "CR-2978" 23 and "Aromatek 245". ${ }^{24}$ The chemical nature of these cigarette paper additives could not be determined, since they are likely treated as proprietary compounds.

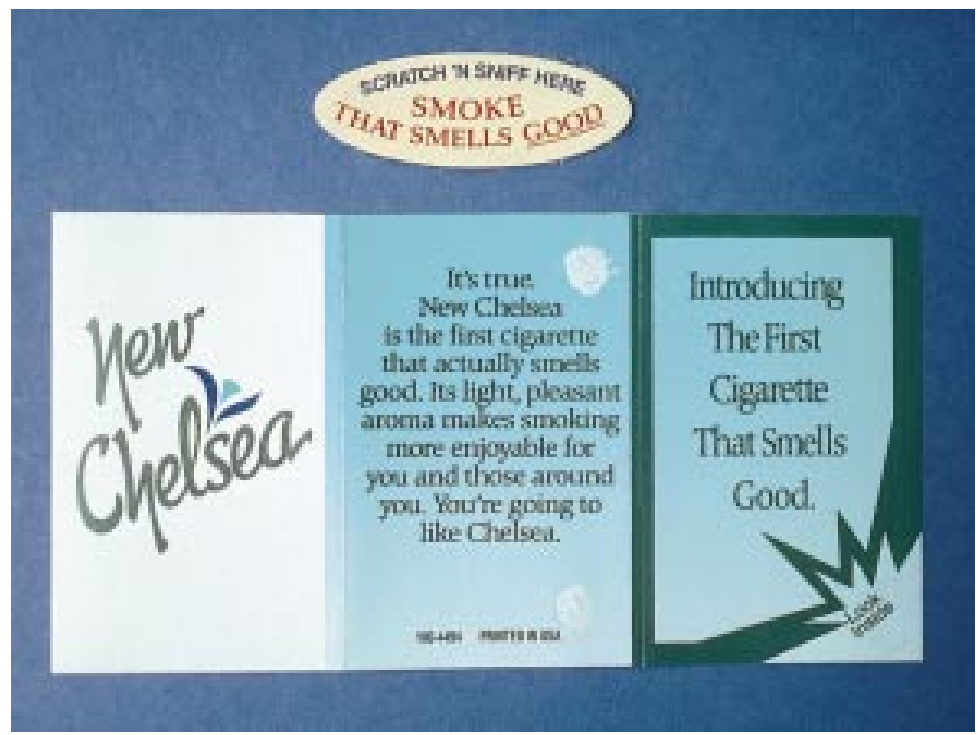

Figure 1 A 1989 advertisement introducing Chelsea, "the first cigarette that smells good". Courtesy of fohn Slade.
Several 1991 RJ Reynolds documents describe "aroma precursors" that were evaluated by a smoking panel. ${ }^{25-28}$ The panel reported that one of these compounds, polyanethole, provided "a noticeable fresher, cleaner and less irritating cigarette sidestream aroma". ${ }^{27}$ Another compound, cinnamic aldehyde pinanediol acetal, produced an aroma that was "slightly sweet, spicy, clean, fresh, dried fruit-like, piney-woody and less cigarette-like than that of the control", and offered some improvement to the sidestream aroma. ${ }^{25}$

Industry patents describe the use of several food derived substances for modifying sidestream odour. Four separate patents cite the use of vanillin for this purpose, ${ }^{29-32}$ while other patents suggest the use of benzaldehyde,,$^{29} 31$ bergamot oil, ${ }^{29} 3033$ cinnamon/ cinnamon extract, ${ }^{3032}$ coffee extract, ${ }^{29}{ }^{33}$ and nutmeg oil ${ }^{29} 33$ among other additives.

Table 1 provides a listing of industry documents pertaining to additives and technologies that reduce sidestream odour.

ADDITIVES THAT REDUCE/MASK SIDESTREAM IRRITATION

A 1987 Philip Morris memorandum notes that efforts are in progress to minimise/mask sidestream smoke irritants, and that the levels of specific irritants, such as acrolein and ammonia, will be determined. ${ }^{34}$ Sidestream flavorants that could mask irritants, such as anethole, were being developed.

In 1988, RJ Reynolds conducted a review of the literature on the influence of additives and flavorants on ETS irritancy. ${ }^{35}$ The review covered nine flavorants that had masking ability, four humectants, casing materials, as well as organic and inorganic acids and salts. Experimentation on lowered levels of casings and tobacco sugars in reducing sidestream and ETS irritation was advised. Masking was recommended in conjunction with other means to reduce irritancy, since its effects alone were judged to be not significant.

A 1984 Brown \& Williamson report indicates that the addition of aluminium sulfate to commercially manufactured "VELVET" cigarette paper considerably reduces sidestream irritation. ${ }^{36}$ The report also describes an initial evaluation of three other compounds, $\mathrm{NaH}_{2} \mathrm{PO}_{4},\left(\mathrm{NH}_{4}\right)_{2} \mathrm{SO}_{4}$, and citric acid, which revealed that only the first two appeared to reduce sidestream irritation.

Table 2 lists documents describing additives and technologies used by the industry to reduce sidestream irritation.

ADDITIVES THAT REDUCE SIDESTREAM VISIBILITY Several cigarette variables, including tobacco weight and blend components, wrapper porosity, and chemical coatings and fillers added to the wrapper, affect the visibility of sidestream smoke. ${ }^{37}$ A 1983 Philip Morris report describes the results of a study in which the amount of visible sidestream smoke emanating from a statically burning cigarette was monitored using light extinction techniques. ${ }^{37}$ Percent light extinction values were assumed to 
Table 1 Additives/technologies that reduce sidestream odour

\begin{tabular}{lll}
\hline Additive & $\begin{array}{l}\text { Document } \\
\text { Bates number }\end{array}$ & Company \\
\hline $\begin{array}{l}\text { Acetylpyrazine, anethole, beta-caryophyllene, } \\
\text { cedrol, ethyl 3-methylvalerate, furaneol, }\end{array}$ & 2001300448 & Philip Morris \\
$\begin{array}{l}\text { limonene, p-anisaldehyde, patchouli alcohol, } \\
\text { phenethyl alcohol, vanillin }\end{array}$ & & \\
"Aromatek 150", "Aromatek 245" & 2023356341 & Philip Morris \\
\hline
\end{tabular}

Table 2 Additives/technologies that reduce sidestream irritation

\begin{tabular}{lll}
\hline Additive & $\begin{array}{l}\text { Document } \\
\text { Bates number }\end{array}$ & Company \\
\hline Aluminium sulfate, $\left(\mathrm{NH}_{4}\right)_{2} \mathrm{SO}_{4}, \mathrm{NaH}_{2} \mathrm{PO}_{4}$ & 566001816 & Brown \& Williamson \\
"XLF-636" & 505005495 & Brown \& Williamson \\
"XLF-662", "XLF-680", "XLF-755" & 566001836 & Brown \& Williamson \\
\hline
\end{tabular}

correlate with the rate at which visible smoke was being emitted.

Large decreases in visible light extinction occurred when magnesium oxide and calcium carbonate fillers were both added to the wrapper. The greatest decreases in visible sidestream were achieved by making modifications to the wrapper by substituting alternative non-soluble fillers, coating it with solutions containing water soluble substances, or changing its porosity. Wrapper coatings of sodium hexametaphosphate; malonic, glutaric, and citric acid; potassium citrate and acetate; and calcium chloride also reduced visible sidestream levels, as did a low level of calcium carbonate filler in the wrapper, and the inclusion of high levels of reconstituted or expanded tobacco in the blend. Future plans for lowering sidestream visibility focused on three approaches: using either of two commercially available wrappers (with modifications and flavour work to mask off-taste and harshness), or using a non-porous wrapper in combination with coatings such as an acetate burn accelerator or substances for improved sidestream aroma. Blend changes and flavours would be incorporated to produce low sidestream visibility with "subjectively desirable" mainstream and sidestream smoke. ${ }^{37}$

Table 3 Additives/technologies that reduce sidestream visibility

\begin{tabular}{|c|c|c|}
\hline Additive & $\begin{array}{l}\text { Document } \\
\text { Bates number }\end{array}$ & Company \\
\hline Albacar chalk, multifex chalk & 2021354113 & Philip Morris \\
\hline $\begin{array}{l}\text { Alumina sol-gel, } \mathrm{MgCO}_{3} \text { sol-gel, phosphoric acid, } \\
\text { potassium pyrophosphate }\end{array}$ & 2020288104 & Philip Morris \\
\hline Calcium carbonate, $\mathrm{Na}_{2} \mathrm{CO}_{3}$ & 2022177532 & Philip Morris \\
\hline $\begin{array}{l}\text { Calcium chloride, citric acid, magnesium oxide, potassium } \\
\text { acetate, potassium citrate, sodium hexametaphosphate }\end{array}$ & 1003638777 & Philip Morris \\
\hline $\begin{array}{l}\text { Glutaric acid, hydromagnesite, malonic acid, potassium } \\
\text { phosphate }\end{array}$ & 2020326633 & Philip Morris \\
\hline Magnesite, potassium succinate & 2023398178 & Philip Morris \\
\hline Magnesium carbonate, $\mathrm{MgCO}_{3}$ sol-gel & 2021327427 & Philip Morris \\
\hline Magnesium hydroxide & $\begin{array}{l}2021553268 \\
505005325\end{array}$ & $\begin{array}{l}\text { Philip Morris Brown } \\
\text { \& Williamson }\end{array}$ \\
\hline Monobasic potassium phosphate, calcium carbonate & $\begin{array}{l}2023394961 \\
2020288066 \\
2020288104 \\
2020326633\end{array}$ & Philip Morris \\
\hline Monopotassium phosphate & 2021354113 & Philip Morris \\
\hline Phosphate, malonic acid & 2020326629 & Philip Morris \\
\hline "Studio 26 blend," "XTH Studio blend" & 2020397399 & Philip Morris \\
\hline
\end{tabular}

Philip Morris also had a "reduced sidestream program" whose goal in 1989 was to develop proprietary wrappers that reduced sidestream visibility by at least $50 \%$, according to a programme outline. ${ }^{38}$

Table 3 lists several industry documents describing additives or technologies that reduce the visibility of sidestream smoke. Other claims for additives that reduce ETS visibility are found in the patent literature, including seven separate claims for the use of calcium carbonate, ${ }^{39-45}$ four for magnesium carbonate, ${ }^{3943446}$ and two each for sodium acetate ${ }^{4748}$ and sodium citrate. ${ }^{42} 47$

ADDITIVES THAT REDUCE SIDESTREAM EMISSIONS A 1990 Brown \& Williamson report describes testing results on coating solutions for reduced sidestream cigarette paper composed of a film forming agent, such as ammonium alginate or sodium carboxymethylcellulose (NaCMC), and a burn additive, such as potassium succinate and/or potassium citrate. ${ }^{49}$ These solutions lowered the permeability of the paper, preventing the sidestream smoke from escaping during smoldering. The report notes that, in general, for hand painted papers, the use of $1-1.5 \%$ of ammonium alginate and $2-6 \%$ of potassium carboxylates on a heavy basis weight cigarette paper can reduce sidestream emissions by at least $50 \%$ compared to a control paper. Further study revealed that ammonium alginate was a better film forming agent on cigarette paper than $\mathrm{NaCMC}$ and also resulted in greater sidestream reduction.

A 1991 Philip Morris document highlights the features of a sidestream reducing mineral, sodium magnesium carbonate $\left[\mathrm{Na}_{2} \mathrm{Mg}\left(\mathrm{CO}_{3}\right)_{2}\right]$, also known as "eitelite". ${ }^{50}$ Eitelite easily leads to a fluxing (dispersing) action during smoking, creating a smoke impervious "ceramic sheath" around the burning cone that reduces sidestream emissions.

In September 1992, Philip Morris received a patent on a cigarette paper for reducing sidestream emissions composed of a single sheet formed from several layers (preferably two) of cellulosic material. ${ }^{51}$ The outer layer has a higher basis weight than the inner layer and also contains a higher level of calcium carbonate filler. The relatively low level of filler in the inner layer helps reduce the burn rate of the paper, thereby aiding in sidestream reduction. If an alkali metal burn chemical (preferably potassium succinate) is added to the paper, it acts as a fluxing agent for the calcium carbonate and also combines with the filler, forming an impervious ash that contributes significantly to the reduction of sidestream smoke, similar to eitelite. The addition of $\mathrm{NaCMC}$ to the bilayer sheet contributes to the imperviousness of the ash, enhancing sidestream reduction. The patent claims that a $17 \mathrm{~mm}$ circumference cigarette made with this paper produces about $40 \%$ less sidestream smoke than a conventional cigarette of the same size.

A 1985 RJ Reynolds patent cited earlier for a double cigarette wrapper containing an alkali 
metal salt describes how these burn additives can be used in combination with other chemicals to reduce sidestream emissions, but cannot effectively do so alone. ${ }^{15}$ The 1990 Brown \& Williamson document on cigarette wrapper coating solutions also discusses the use of burn additives with film forming agents that reduce sidestream emissions. ${ }^{49}$

RJ Reynolds conducted several research projects to develop reduced sidestream products. "Program RS" ("reduced sidestream") investigated the use of carbonised tobacco as a filler to dilute the blend and reduce sidestream smoke. ${ }^{52}$ The product for "Project CC" (meaning unknown) was being developed using two different delivery systems: a double wrap and a single wrap. ${ }^{53}$

Table 4 lists several industry documents describing additives that reduce sidestream emissions.

INDUSTRY SIDESTREAM "BRAND PROJECTS" Cigarette manufacturers conducted various projects in which ETS altering additive technology was incorporated into product prototypes. Table 5 provides a partial list of these projects.

\section{Project Stealth}

Two 1990 Philip Morris documents describe Project Stealth as a product with low tar, low smoke $(70 \%$ less smoke from the lit end, which was later changed to $50 \%$ ), and low odour. ${ }^{64}$ Project Stealth, which was to be marketed under the brand name of either Select or Choice, eliminated odour by producing less smoke and employing a "natural screening system" in the filter that absorbed odour, a technology known internally as "Aromatech". Stealth was initially to be positioned as "help[ing] smokers feel better about smoking in social situations, ${ }^{6}$ which was viewed as a "social benefit". ${ }^{55}$

However, consumer research conducted by Leo Burnett USA, an advertising agency, revealed that while the reduction in smoke and

Table 4 Additives that reduce sidestream emissions

\begin{tabular}{|c|c|c|c|c|}
\hline \multicolumn{3}{|l|}{ Additive } & $\begin{array}{l}\text { Document } \\
\text { Bates number }\end{array}$ & Company \\
\hline \multicolumn{3}{|l|}{$\mathrm{Na}_{2} \mathrm{Mg}\left(\mathrm{CO}_{3}\right)_{2}$ (eitelite) } & $\begin{array}{l}2022939206 \\
2022939207\end{array}$ & Philip Morris \\
\hline \multicolumn{3}{|c|}{$\begin{array}{l}\text { Ammonium alginate with potassium } \\
\text { succinate as burn additive }\end{array}$} & 575103432 & Brown \& Williamson \\
\hline \multicolumn{3}{|c|}{$\begin{array}{l}\text { Ammonium alginate, sodium carboxymethylcellulose } \\
\text { (NaCMC), with potassium carboxylates (citrate, } \\
\text { succinate) as burn additives, } \mathrm{MgO}\end{array}$} & 608002369 & Brown \& Williamson \\
\hline \multicolumn{3}{|c|}{$\begin{array}{l}\mathrm{NaCMC} \text { with monoammonium phosphate } \\
\text { and potassium succinate as burn additives }\end{array}$} & 620692855 & Brown \& Williamson \\
\hline \multicolumn{5}{|c|}{ Table 5 Industry sidestream "brand projects" } \\
\hline Project name & Company & \multicolumn{2}{|c|}{ Additive/technology } & Altered ETS attribute \\
\hline Stealth & Philip Morris & \multicolumn{2}{|c|}{ "Aromatech" } & Visibility/aroma \\
\hline Cosmo & Philip Morris & \multicolumn{2}{|c|}{ Less tobacco } & Visibility \\
\hline Aquarius & Brown \& Williamson & \multicolumn{2}{|c|}{$\begin{array}{l}\text { Expanded tobacco, } \\
\text { low sidestream paper }\end{array}$} & Emissions/visibility \\
\hline YW (Young Women) & RJ Reynolds & \multicolumn{2}{|c|}{ Vanillin } & Aroma \\
\hline Ambrosia & Philip Morris & \multicolumn{2}{|c|}{$\begin{array}{l}\text { “Aromatek 150," } \\
\text { “Aromatek 245," } \\
\text { vanillin }\end{array}$} & Aroma \\
\hline
\end{tabular}

odour were considered important, it was not viewed by smokers as significant enough to allow them to feel comfortable smoking around non-smokers. ${ }^{55}$ Rather, smokers saw Stealth as a way to help reduce the lingering cigarette odour in their clothes, home, and car. Therefore, Stealth's positioning was changed to "the first cigarette that doesn't leave a stale, lingering odor after smoking". ${ }^{54}$ The Burnett report notes that this marketing strategy still had an implicit social benefit, since smokers would receive fewer complaints from non-smokers about lingering odour. ${ }^{55}$

Interestingly, a 1991 Philip Morris brand review of new products describes the beneficial marketing implications for Stealth as a result of the US Environmental Protection Agency having classified ETS as a group A (known human) carcinogen:

- "More smoking bans in public places as well as in private business.

- Anti-smokers group will ensure maximum publicity, new powerful tactic to increase the guilt of smokers.

- Heighten smokers' awareness of second hand smoke.

- Potential opportunities for more socially acceptable cigarettes."

Project Cosmo

A 1987 Philip Morris report on Project Cosmo states that the product will be positioned as an "ultra slim" cigarette that contains less tobacco than conventional cigarettes and generates less sidestream smoke, with a "stylish and fashionable" consumer perception. ${ }^{57}$ In developing brand names to communicate this positioning, Philip Morris explored three alternative concepts: "A la Capri," "Cartier", and "Socially Acceptable". ${ }^{57}$ The first two categories would be targeted toward sophisticated, stylish young women, with Cartier being more "upscale", like the famed jeweller. The "Socially Acceptable" concept would encompass any one of the following three more practical avenues: a Benson \& Hedges "flanker" (to be more "gender neutral" than A la Capri or Cartier, in order to ensure a broader appeal), a Merit line extension (emphasising a "technological breakthrough"), or a "free standing" product (also gender neutral) to be portrayed as: " . . . [A] diet smoke, emphasizing less tobacco, low tar, and low sidestream smoke. This aggressive positioning is likely to open up a new category of smoking."

The report indicates that for the "Socially Acceptable" category there would be no direct mention or pictures in the advertising concerning low sidestream emissions. Instead, copyline would be used that implies product "benefits" in a "subtle, 'soft-sell' manner". ${ }^{57}$

Project Aquarius

According to a 1989 Brown \& Williamson product development report, the objective of Project Aquarius was: "[T]o develop a low sidestream $100 \mathrm{~mm}$ cigarette with a mainstream delivery of 10 to $12 \mathrm{mg}$ of tar, and to out-perform VANTAGE EXCEL 100 in both sidestream reduction and taste." ${ }^{.58}$ 
Brown \& Williamson outlined a strategy for meeting this objective: (1) reduce total sidestream emissions by using high levels $(>70 \%)$ of expanded tobacco (thereby reducing the amount of tobacco burned); and (2) use a low sidestream paper that reduces visible sidestream, but does not contribute an offtaste to the mainstream smoke. ${ }^{58}$ However, the use of expanded tobacco resulted in diminished mainstream smoke quality and reduced puff count. To improve smoke quality, Brown \& Williamson evaluated for expansion new blends containing high concentrations of glycerin. After expansion, magnesium chloride and/or ammonium chloride were added to reduce the burn rate, thereby increasing the puff count. Testing of crude prototypes that combined the best low density blends and low sidestream papers were judged to be "highly competitive on both sensory and sidestream reduction". ${ }^{59}$

The report also notes that "Project Taurus", which was a previous attempt at making a low sidestream cigarette, failed because of unacceptable smoke taste. ${ }^{58}$ This was caused by the use of a commercial low sidestream paper that contained magnesium oxide as a co-filler.

\section{Project $Y W$}

A 1987 RJ Reynolds project summary positions "Young Women" as "a breakthrough product with a perfected blend so smooth and refined that it even has a noticeably fresher aftertaste and pleasant smoke aroma" ${ }^{60}$ Of the 54 sidestream aromas screened for this product, the preferred scents fell within the category of "edible, tasty aromas", with the top candidates being vanilla, toffee, milk chocolate, coconut, and marshmallow. ${ }^{13}$ Reynolds settled on vanillin as the "only feasible aroma candidate". ${ }^{61}$ However, after an initial product test, failure to address the issue of fresh aftertaste led to the project being dropped. ${ }^{60}$ The work was then transferred to "Project TF", which had a similar product concept and target population. ${ }^{62}$

"Project Ambrosia"

A 1990 Philip Morris memorandum describes the results of subjective tests performed on three low sidestream models of Ambrosia cigarettes made with: (1) low sidestream paper only; (2) low sidestream paper with "Aromatek 245"; and (3) low sidestream paper with "Aromatek $150 " .{ }^{63}$ The cigarettes were rated against Marlboro Lights controls for differences in smoke intensity, irritation, acceptability, and added odour. The test model with low sidestream paper alone was rated significantly lower on smoke intensity than the control. The Aromatek 150 model was rated significantly lower on irritation and significantly higher on added odour, which was described as "vanillin and sweet". Generally, very little added odour was detected for the models with low sidestream paper only and Aromatek 245. There were no significant differences in acceptability.
A 1992 memorandum describes the results of an evaluation of two types of Ambrosia products for sidestream odour acceptability as perceived in a room environment. ${ }^{64}$ "Ambrosia I" altered the aroma of the ambient air by releasing a vanilla like odour, while "Ambrosia II" reduced the amount or odour of the sidestream. Although all Ambrosia I and II products were found to improve the character of room aroma, the overall change, while statistically significant, was small. Furthermore, none of them could be termed "low odour" when compared to a fresh air environment. They were, however, viewed as representing "a step in the right direction".

ETS ALTERING ADDITIVES AND SMOKE TOXICITY Industry documents reviewed pertaining to additives that alter ETS show little evidence of testing for changes in mainstream or sidestream smoke constituent levels or toxicity. Few studies measured changes in the concentration of specific constituents, reporting at most the levels of sidestream total particulate matter (TPM). A 1983 Philip Morris report described earlier measured the effect of several cigarette variables (that is, tobacco weight, blend components, wrapper coatings, and fillers) on the levels of sidestream TPM. ${ }^{37}$ The report provides the sidestream and mainstream deliveries of selected compounds, including tar, nicotine, carbon monoxide, nitrous oxide, aldehydes, and hydrogen cyanide, upon application of various additives to the cigarette paper. However, the study conclusions are drawn from the overall effects of these additives on the level of sidestream TPM as an indicator of smoke visibility, rather than on the levels of individual constituents themselves. One observation is that carbon monoxide deliveries were increased with papers containing sodium aluminate and sodium silicate.

The reviewed industry studies also failed to conduct a thorough analysis of reductions in the levels of major toxic gas or particulate phase constituents in mainstream or sidestream smoke, such as the carcinogenic tobacco specific $\mathrm{N}$-nitrosamines (TSNA). This is of particular concern, since individual TSNA levels in sidestream smoke, the major source of ETS, can be more than 20 times higher than in mainstream smoke (as in the case of NNK), ${ }^{65}$ and could conceivably increase in concentration if the additive technology reduces the burn temperature of the cigarette cone. A 1981 Lorillard memorandum describes a new cigarette paper that was found to reduce overall sidestream emissions, but increased the mainstream yield of certain toxins, including the TSNA $\mathrm{N}$-nitrosonornicotine and benzo(a)pyrene, which are both highly carcinogenic. ${ }^{66}$ Although design changes were subsequently made to reduce the levels of these compounds, ${ }^{67}$ it is possible that some of these changes might actually pose a greater ETS exposure risk. This review found no documents showing evidence of the manufacturers conducting standard toxicity testing 
(that is, Ames test, mouse skin painting, inhalation studies) to determine the potential impact of ETS altering additives on health.

\section{Conclusions}

This review of the tobacco industry documents shows how manufacturers were concerned about the lack of "social acceptability" of their cigarettes caused by negative perceptions of secondhand smoke among both smokers and non-smokers. Cigarette additives were developed along with other product design changes to reduce or mask the aroma, visibility, and irritation of sidestream smoke, and less frequently, to lower actual smoke emissions. Many of these additives were incorporated into special "brand projects" for testing, some of which later entered the marketplace, such as Chelsea/Horizon and Virginia Super Slims. Very little research was found in this review regarding the effect of these additives on the toxicity of mainstream and sidestream smoke or the levels of individual smoke constituents. In addition, there was little evidence to suggest that tobacco manufacturers sought to fully inform consumers of the product changes they were designing and implementing. These are important considerations, since the use of sidestream altering additives could increase non-smokers' involuntary exposure to ETS by reducing the normal warning signs of exposure to smoke toxins. Another major concern is that women of childbearing age are a prime target group for these brand modifications. Thus, women smokers with young children may increase their child's risk of developing respiratory diseases through increased ETS exposure if they themselves are not bothered by the smoke.

In 1984, the federal government began requiring cigarette manufacturers to disclose annually a list of additives placed in the cigarette tobacco rod to the Office on Smoking and Health. However, they are not required to report substances that are added to the wrapper paper or filter, or the quantities of additives used by brand, which makes it virtually impossible to study which products employ ETS altering technologies. Also, the vast majority of documents on the industry's use of cigarette additives, obtained through civil smoking and health litigation, are not available to public health officials because they are protected under a Minnesota court order as trade secrets.

Since 1988, Canada has mandated disclosure of tobacco additives by quantity and brand (although the reported information has not been made public), and the European Commission is currently considering a similar requirement as part of a proposal directive. In 1996, the Massachusetts legislature enacted the Tobacco Disclosure Act (Massachusetts General Laws, chapter 94, section 307B), which requires manufacturers to disclose additives placed in any part of the cigarette in descending order by weight and brand. However, the state was sued by the major tobacco manufacturers and enjoined by the federal court from receiving the first additive reports due in December 1997, based on the industry claim that the disclosure requirements constituted the taking of valuable industry trade secrets. The state is currently awaiting the court's decision on the constitutionality of the law.

This review provides compelling evidence as to why governmental entities should have access to additives information and demonstrates the need for appropriate regulatory action to protect the public from the dangers of smoking and involuntary exposure to ETS. Tobacco manufacturers should be required to disclose the name and concentration of each additive used by brand and its intended purpose. Often, the uses publicly claimed by the industry are very different from those revealed in the corporate documents and patents. All documents on tobacco additives obtained in discovery from tobacco manufacturers that remain currently under seal should be made available to regulatory authorities. Whether or not this information should be made publicly available is subject to debate, but at a minimum government entities should receive it in order to conduct appropriate research. Manufacturers also should be required to test cigarette additives thoroughly to demonstrate that they do not increase the health risks of involuntary exposure to ETS. Those found to increase health risks, including the toxicity of the mainstream and sidestream smoke, should be removed. More research is needed, including product testing to identify brand design issues and to warn the public of potential harm.

The Federal Food and Drug Administration (FDA) is the appropriate regulatory agency to address the issue of tobacco additives disclosure. In 1996, the FDA asserted its jurisdiction over tobacco products as drugs and nicotine delivery devices under the Food, Drug, and Cosmetic Act, but was sued by the tobacco industry in federal court, which ruled that the agency lacked such regulatory authority. The appealed decision was recently upheld by the Supreme Court. In the absence of FDA authority, individual states must address this issue through their public health or consumer protection authorities.

1 US Environmental Protection Agency. Respiratory health effects of passive smoking. Fact sheet. Washington DC: US Effects of passive smoking. Fact sheet. Washington

2 Taylor AE, Johnson DC, Kazemi H. Environmental tobacco smoke and cardiovascular disease: a position paper from the council on cardiopulmonary and critical care, American Heart Association. Circulation 1992;86:699Americ

3 Glantz SA, Slade J, Bero LA, Hanauer P, Barnes DE. The cigarette papers. Berkeley and Los Angeles, California: University of California Press, 1996:391-435.

4 Farone WA. Memo to RB Seligman and LF Meyer. Re: Idea session on beneficial additives. Philip Morris, Inc, February 16, 1981. Bates No. 2026229625/9629.

5 Jones, C. "Low-toxin cigarette created/35 potential hazards reduced, Philip Morris says." Richmond Times-Dispatch, March 18, 1998.

6 Philip Morris, Inc. Project Stealth [brand plan]. Philip Morris, Inc., July 1990. Bates No. 2049400355.

7 Philip Morris, Inc. Review of past "social" cigarettes. Philip Morris, Inc, September 1991. Bates No. 2045628701/ 8718

8 Philip Morris, Inc. Low sidestream/low odor research. Philip Morris, Inc, January 1993. Bates No. 2021351131/ 1179.

9 Philip Morris, Inc. 1993-1997 Philip Morris USA R\&D strategic plan. Philip Morris, Inc, March 2, 1992. Bates No. $2021522925 / 3041$. 
10 Anholt RRH, Simon SA. Proposal for Collaborative Research with the Philip Morris Company. Development
of trigeminal bioassays for the quantitative measurement of trigeminal bioassays for the quantitative measurement of sidestream smoke induced nociceptio
Inc, 1988. Bates No. 2022945748/5772.

11 Seeman JI. Memo to Distribution (J Charles, et al). Re: Trigeminal studies in conjunction with Professor Robert Anholt. Philip Morris, Inc, January 26, 1988. Bates No. 2024770079.

12 Hudson AB. Memo to Dr AW Spears. Re: Socially acceptable cigarette. Lorillard Tobacco Co, November 8 , 1979. Bates No. 00360191/0193.

13 Cranford JM, Jr. Letter to Mr Jordan Stanley, Young \& Rubicam, Inc, New York, NY. RJ Reynolds Tobacco Co, February 21, 1986. Bates No. 505217742-7745.

14 Miller JH. Memo to Dr MF Dube. Re: Project TF-next steps. RJ Reynolds Tobacco Co, June 10, 1987. Bates No. 505618412-8413.

15 US Patent No. 4,561,454. "Smoking article having reduced sidestream smoke." RJ Reynolds Tobacco Co. (assignee-atissue), December 31, 1985 .

16 US Patent No. 5,107,865. "Smoking articles." Brown \& Williamson Tobacco Corp (assignee-at-issue), April 28, 1992 .

17 Cohen PS. Memo to Ms MR Savoca. Re: Sidestream irritation team brainstorming. RJ Reynolds Tobacco Co, July 25, 1989. Bates No. 506902914-2917. 18 RJ Reynolds Tobacco Co. Chelsea advertising pamphlet,
1989.

19 Farone WA. Memo to RB Seligman and LF Meyer. Re: Idea session on reducing sidestream. Philip Morris, Inc, February 4, 1981. Bates No. 1003225256/5262.

20 Southwick R. Memo to E Gee. Re: Odor modification of sidestream smoke. Philip Morris, Inc, March 3, 1988. Bates No. 2001300448

21 Tafur S, Ferguson R. Memo to Patent Counsel. Re: Invention record. Preliminary disclosure for consideration of patentability. Philip Morris, Inc, December 23, 1988. of patentability. Philip
Bates No. 2026343583.

22 Tafur S. Memo to RN Ferguson. Re: Evaluation of "Smellrite." Philip Morris, Inc, July 18, 1989. Bates No. rite." Philip Mor

23 Comes R, Seeman JI, Yatrakis G. Memo to Distribution (Flavor Committee, et al). Re: Smoking studies on CR-2978. Philip Morris, Inc, January 1993. Bates No 2057772000/2001

24 Izac RR, Core M, Houminer Y. Memo to RN Ferguson. Re: Analysis of mainstream, sidestream, and butts from cigarettes coated with Aromatek 245. Philip Morris, Inc, August 3, 1989. Bates No. 2022194616/4618.

25 Lawrence BM. Memo to Dr ME Stowe. Re: Weekly highlights. Flavor Division. RJ Reynolds Tobacco Co, June 18, 1991. Bates No. 511619744

26 Redding JW. Memo to Brian M Lawrence. Re: Propenyl guaiacol glucosides. RJ Reynolds Tobacco Co, March 5 , 1991. Bates No. 511334080

27 Redding JW. Memo to Brian M Lawrence. Re: Poly anethole evaluation. RJ Reynolds Tobacco Co, April 25, 1991. evaluation. RJ Reynol
Bates No. 511334075.

28 Redding JW. Memo to Brian M Lawrence. Re: Sidestream evaluation of cinnamic aldehyde methyl glucopyranoside acetal. RJ Reyno

29 US Patent No. 4,076,853. "Flavoring with substituted norbornane derivatives." International Flavors \& Fragrances, Inc (assignee-at-issue), February 28, 1978.

30 US Patent No. 5,144,964. "Smoking compositions contain ing a flavorant-release additive." Philip Morris, Inc (assignee-at-issue), September 8, 1992.

31 US Patent No. 5,320,131. "Method of providing an aroma and flavor precursor for smoking articles." RJ Reynolds Tobacco Co (assignee-at-issue), June 14, 1994.

32 US Patent No. 5,494,055. "Aroma mixtures for incorporation into coverings for smokeable tobacco goods." $\mathrm{H} \mathrm{F} \&$ Ph F Reemtsma GmbH \& Co, Hamburg, DE (assignee-atissue), February GmbH \&

33 US Patent No. 4,627,449. "Process for augmenting or enhancing aroma or taste of smoking tobacco and smoking tobacco article using aldehyde composition." International tobacco article using aldehyde composition." International Flavors \&

34 Gauvin PN. Memo to Distribution (Bates K, et al). Re: Sidestream smoke aroma. Philip Morris, Inc, August 25, 1987. Bates No. 2020090105

35 Perfetti TA. Memo to MS Savoca. Re: Influence of additive[s] and flavorants on ETS irritancy. RJ Reynolds Tobacco Co, November 22, 1988. Bates No. 506798695 8706 .

36 St Charles FK. The effect of aluminum sulfate on Ecusta's velvet paper/325. Brown \& Williamson Tobacco Corp. File note, March 14, 1984. Bates No. 566001816/1819.

37 Gunst KW. Sidestream visibility of a statically burning cigarette. Philip Morris, Inc, August 19, 1983. Bates No. $1003638777 / 8804$.

38 Ferguson RN. Memo to Dr EB Sanders. Re: Outline of 1989 plans for reduced sidestream program. Philip
Morris, Inc, December 29, 1988. Bates No. 2057772366/ 2368 .
39 US Patent No. 3,744,496. "Carbon filled wrapper for smoking article." Olin Corp. (assignee-at-issue), July 10, 1973. 40 US Patent No. 4,420,002. "Wrapper for smoking articles and method." Olin Corp. (assignee-at-issue), December 13, 1983.

41 US Patent No. 4,450,847. "Wrapper for smoking articles and method." Olin Corp. (assignee-at-issue), May 29, 1984.

42 US Patent No. 4,461,311. "Method and smoking article wrapper for reducing sidestream smoke." Kimberly-Clark Corp. (assignee-at-issue), July 24, 1984.

43 US Patent No. 4,721,120. "Smoking articles." British American Tobacco Co, Ltd. (assignee-at-issue), January $26,1988$.

44 US Patent No. 4,805,644. "Sidestream reducing cigarette paper." Sidestream reducing cigarette paper." KimberlyClark Corp. (assignee-at-issue), February 21, 1989.

45 US Patent No. 5,092,353. "Cigarette." RJ Reynolds Tobacco Co (assignee-at-issue), March 3, 1992.

46 US Patent No. 5,092,306. "Magnesite composition filler for smoking article wrapper." Philip Morris, Inc (assignee-atissue), March 3, 1992

47 US Patent No. 4,231,377. "Wrapper for smoking articles containing magnesium oxide." Olin Corp. (assignee-atissue), November 4, 1980.

48 US Patent No. 4,624,268. "Smoking articles." British American Tobacco Co, Ltd. (assignee-at issue), November 25, 1986.

49 Chao LC, Tang JY, Houpt ST, St. Charles FK. Memo to Distribution (J.S. Wigand, et al). Re: Low sidestream cigarette paper development/269. Brown \& Williamson Tobacco Corp, December 17, 1990. Bates No. 608002369/2375.

50 Philip Morris, Inc filename: eitelite.patent.910514. Philip Morris, Inc, May 14, 1991. Bates No. 2022939207/9218.

51 US Patent No. 5,143,098. "Multiple layer cigarette paper for reducing sidestream smoke." Philip Morris, Inc (assignee-at-issue), September 1, 1992

52 RJ Reynolds Tobacco Co. Program RS: reduced sidestream cigarette. RJ Reynolds Tobacco Co, 1985. Bates No. 504655958-5963.

53 RJ Reynolds Tobacco Co. Reduced sidestream technology. Project CC-background. Project CC-research. RJ Reynolds Tobacco Co, January 6, 1988. Bates No. 506685030-5038.

54 Philip Morris, Inc. Project Stealth: focus group topline. Philip Morris, Inc, August 30, 1990. Bates No. 2049400339/0340.

55 Beardslee W. Letter to Mr Louis Suwarna, Philip Morris, Inc. Re: Project Stealth strategy. Philip Morris, Inc, September 25, 1990. Bates No. 2044124149/4151.

56 Philip Morris, Inc New Products Brand Review. Philip Morris, Inc, September 19, 1991. Bates No. 2043982807/ 2850.

57 Interbrand Corporation. Naming strategy report prepared for Philip Morris, USA. Project Cosmo. Revised-July 14, 1987. Philip Morris, Inc. Bates No. 2049434829/4846.

58 Templeton LK. Phase I development of a low sidestream cigarette. Brown \& Williamson Tobacco Corp, October 20, 1989. Bates No. 570243847/3853.

59 Brown \& Williamson Tobacco Corp. Status of Barclay Y1 Conventionals; Capri; Ultra; Sunbelt; Zircon; Aquarius. Brown \& Williamson Tobacco Corp, April 19, 1990. Bates No. $562503093 / 3096$

60 RJ Reynolds Tobacco Co. Project YW. RJ Reynolds Tobacco Co, 1987. Bates No. 505936285-6292.

61 RJ Reynolds Tobacco Co. YW product development. RJ Reynolds Tobacco Co, 1986. Bates No. 505217753-7762.

62 Miller JH. Memo to DN Lauco. Re: Project YW quantitative concept test-revised brand perspective. RJ Reynolds Tobacco Co, August 4, 1987. Bates No. 507372369-2370.

63 Smith AD. Memo to Ms Linda Wettle. Re: Subjective testing of low-sidestream Ambrosia models in the PACT room. Philip Morris, Inc, June 14, 1990. Bates No. $2023356341 / 6343$.

64 Jeltema M. Memo to L Suwarna. Re: Sensory testing of sidestream aroma. Philip Mort

65 US Department of Health and Human Services. Reducing the health consequences of smoking: 25 years of progress. A report of the Surgeon General, 1989. Rockville, Maryland: Public Health Service, Centers for Disease Control, Office (CDC) 89-8411.)

66 Jessup TD. Memo to AB Hudson. Re: reduced sidestream cigarette. Lorillard Tobacco Co, February 25, 1987. Bates No. 80641174/1175.

67 Hudson AB. Memo to FJ Schultz. Re: Reduced sidestream [smoke] cigarette. Lorillard Tobacco Co, June 25, 1987. Bates No. 87091446/1448. 